\title{
Barriers to Oral Care Provision in Homebound and Institutionalized Elderly
}

\author{
Kamal Shigli ${ }^{1}$, Sushma Nayak ${ }^{2}$
}

International Journal of Prosthodontics and Restorative Dentistry (2020): 10.5005/jp-journals-10019-1298

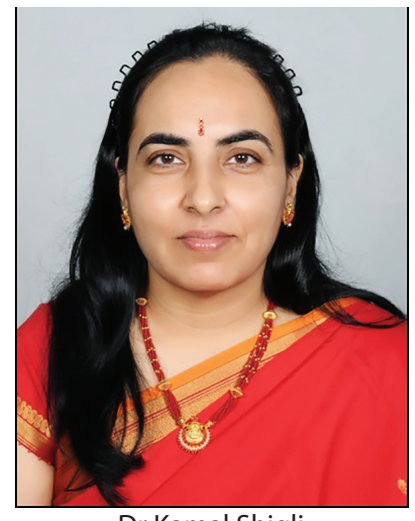

Dr Kamal Shigli
The advances in medical science and technology have led to an increase in life expectancy. Globally, the 60-plus population is on the rise. In Asia, the increase in the proportion of the elderly is predicted from 10.5 to $22.4 \%$ while in India, the 60-plus population is projected to increase from 8 to $19 \%$ by 2050 .

Majority of the elderly population $(80 \%)$ live in rural India, 30\% below the poverty line, $73 \%$ illiterate, $45 \%$ experience chronic diseases, and $5.4 \%$ are immobile. $^{2}$ In addition most of the elderly have multimorbidity which presents an additional hurdle. ${ }^{3}$ Another challenge being posed by increased life expectancy is dependency for care. Approximately three fourth of the Indian elderly are either fully or partially dependent on others with female predominance. The lack of universal social security and health programs has led to an increase in the dependency of India's elderly population.

There are around 1000 old age homes in India and their utilization rate of dental services is poor. Provision of oral care to the dependent elderly is important considering the link between oral and systemic diseases. Dependency leads to a shift in priorities of the patient resulting in neglect of the oral cavity. ${ }^{4}$ The common dental problems include missing teeth due to dental caries and periodontal disease, xerostomia and oral cancer. Lack of awareness regarding the need for dental treatment, financial constraints to support expensive dental treatment, access to care, fear, and cognitive impairments may contribute as major barriers for patients to seek oral care provision. ${ }^{5}$ The attitude of the elderly, as well as the caregivers, perceiving dental problems to be a normal part of ageing could pose a major barrier. This could be tackled by periodic community awareness campaigns on the importance of geriatric oral health and also palliative dental care.

"Dental care at home or at destinations of residents" is a concept yet to develop in India. The "Homebound residents" and the "Nursing homebound residents" refer to the group of elderly who are unable to be independent. In cases of severe impairment, they may be unable to leave the house without aid or become institutionalized in the nursing homes. They are considered being impaired, frail, and may have no less than one chronic medical disability. They may exhibit dependency to perform even the routine oral hygiene measures making them susceptible to oral ailments. ${ }^{6}$ The management of this population is different than the general population in terms of medical and oral health. ${ }^{7-10}$
${ }^{1}$ Department of Prosthodontics, DY Patil Dental School, Pune, Maharashtra, India

${ }^{2}$ Public Health Dentist, Bengaluru, Karnataka, India

Corresponding Author: Kamal Shigli, Department of Prosthodontics, DY Patil Dental School, Pune, Maharashtra, India, e-mail: kamalshigli@ yahoo.co.in

How to cite this article: Shigli K, Nayak S. Barriers to Oral Care Provision in Homebound and Institutionalized Elderly. Int J Prosthodont Restor Dent 2020;10(4):140-141.

Source of support: Nil

Conflict of interest: None

Unfortunately our training does not cater to address needs of the elderly in a holistic manner. ${ }^{8}$ Not many dentists provide treatment to homebound patients and when provided it ranges from emergency care to minimum intervention. The possible reasons being lack of training leading to lack of confidence in providing patient care in a non-dental environment, communication difficulties, loss of practice time, and lack of referrals from the nursing homes to the dentist., ${ }^{9,10}$ The associated medical problems and polypharmacy may also deter the professionals from providing dental care.

The United Nations has declared 2021-2030 as the "Decade of Healthy Ageing" and a concerted effort is being made to improve the life of elderly. National Centre for Ageing and regional geriatric centres are envisioned to render geriatric care, develop trained workforce etc. This opportunity could be utilized to improve geriatric dental care as well as domiciliary care. Currently domiciliary dental care is available in a few metro cities. Interprofessional education and training programmes with those involved in providing care to the elderly may help in rendering care to dependant elderly. ${ }^{11}$ In addition, there can be online geriatric dentistry related resource centres for the practitioners. ${ }^{12}$ Short term practical training courses should be designed for provision of dental care in outdoor setting using portable equipment. We also need to highlight the need for dental care of institutionalized or homebound among the caregivers by disseminating information, conducting community reach programmes etc.

Public funding of dental care for homebound and institutionalized could help in increasing the utilization of dental care for this group of patients.

Literature has highlighted the lack of development in this field. However now the time has come that some firm steps are taken in this direction. Mandatory adopting of old age homes by institutions could help the old age homes as well as provide experience to the students in managing the very old. To sum up, keeping the above barriers in mind the dentist must be patient with these patients and empathetic toward them. Our aim should be to "Reach out to 
those who cannot reach us" by emphasizing treatment and care for the homebound and institutionalized patients.

\section{References}

1. United Nations Population Fund. Caring for our elders: early responses. India Ageing Report 2017. https://india.unfpa.org/sites/ default/files/pub-pdf/India\%20Ageing\%20Report\%20-\%20201 7\%20\%28Final\%20Version\%29.pdf Accessed March 03, 2021.

2. Shah N. Oral health care system for elderly in India. Geriatr Gerontol Int 2004;4:S162-S164. DOI: 10.1111/j.1447-0594.2004.00187.x.

3. Pati $S$, Sinha R, Mahapatra $P$, et al. Management of geriatric multimorbidity in old age home residents: an emerging issue in India. Geriatr Gerontol Int 2021;21(3):338-339. DOI: 10.1111/ggi.14137.

4. Baumgartner W, Schimmel M, Müller F. Oral health and dental care of elderly adults dependent on care. Swiss Dent J 2015;125(4):417-426.

5. Dolan TA, Atchison KA. Implications of access, utilization and need for oral health care by the non-institutionalized and institutionalized elderly on the dental delivery system. J Dent Educ 1993;57(12): 876-887. DOI: 10.1002/j.0022-0337.1993.57.12.tb02819.x.
6. Panchbhai AS. Oral health care needs in the dependant elderly in India. Indian J Palliat Care 2012;18(1):19-26. DOI: 10.4103/09731075.97344.

7. Shigli K, Nayak SS, Kusurkar RA, et al. Use "LATCHeS" to communicate with elderly patients. Spec Care Dentist 2020;40(4):390-392. DOI: 10.1111/scd.12474.

8. Shigli K, Nayak SS, Jirge V, et al. Current status of gerodontology curriculum in India and other parts of the world: A narrative review. Gerodontology 2020;37(2):110-131. DOI: 10.1111/ger.12461.

9. Lewis A, Wallace J, Deutsch A, et al. Improving the oral health of frail and functionally dependent elderly. Aust Dent J 2015;60(Suppl 1): 95-105. DOI: 10.1111/adj.12288.

10. da Rosa SV, Moysés SJ, Theis LC, etal. Barriers in access to dental services hindering the treatment of people with disabilities: a systematic review. Int J Dent 2020;2020:9074618. DOI: 10.1155/2020/9074618.

11. Shigli K, Nayak SS, Sharma S, et al. Interprofessional education-a case for gerodontology training. Gerontol Geriatr Educ 2020;9:1-15. DOI: 10.1080/02701960.2020.1843453.

12. Matear D, Gudofsky I. Practical issues in delivering geriatric dental care. J Can Dent Assoc 1999;65(5):289-291. 